\title{
Princípios de funcionamento de diferentes métodos de dessalinização de água do mar e análise paramétrica de um dessalinizador de múltiplo efeito (MED)
}

\section{Work principles of different methods of seawater desalination and parametric analysis of a multiple effect desalination (MED)}

Article Info:

Article history: Received 2019-01-23 / Accepted 2022-01-17 / Available online 2022-01-17

doi: $10.18540 /$ jcecvl8iss1pp13833-01-14e

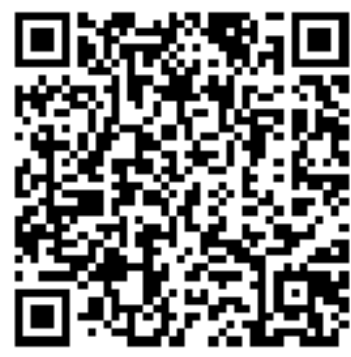

Antonio Marcos de Oliveira Siqueira

ORCID: https://orcid.org/0000-0001-9334-0394 Universidade Federal de Viçosa, Viçosa, MG, Brasil

Alexia Lara Souza Martins

Universidade Federal de Viçosa - UFV, Viçosa, MG alexialsmartins@gmail.com Erick Eduardo Dias Viana

Universidade Federal de Viçosa - UFV, Viçosa, MG erickdiasviana@gmail.com

\section{Resumo}

O presente trabalho foi idealizado a partir de uma demanda real da Prefeitura de Fortaleza/CE de projetos de dessalinização de água do mar para abastecimento de água doce para a cidade. Em virtude disso, incialmente, explorou-se na forma de uma revisão bibliográfica os princípios de funcionamento de diferentes processos de dessalinização, suas capacidades produtivas e requerimento energético. Concluiu-se então que a Dessalinização por Múltiplo Efeito (MED) é o método mais promissor, por apresentar baixo consumo de energia se comparado aos métodos mais utilizados, pela potencialidade de autossuficiência da energia térmica requerida e por não ser necessário um pré-tratamento tão complexo, uma vez que sua operação ocorre a uma temperatura moderada. Na sequência, foi realizado um estudo de caso, envolvendo a modelagem matemática e a simulação numérica de uma instalação de dessalinização MED, utilizando-se o software Engineering Equation Solver (EES). Por fim, realizou-se uma análise paramétrica, que mostrou que o modelo utilizado para estudo de caso apresenta um bom desempenho, além de ser adaptável para a implementação em uma série de possibilidades. Desta forma, estudos de caso na área podem acarretar em modelos práticos que possam suprir as demandas existentes, bem como a adaptação de métodos como o em questão.

Palavras-chave: Dessalinização; MED; EES.

\begin{abstract}
The present work was conceived from a real demand from the City Hall of Fortaleza/CE for seawater desalination projects to supply fresh water to the city. As a result, initially, the working principles of different desalination processes, their productive capacities and energy requirements were explored in the form of a literature review. It was then concluded that Multiple Effect Desalination (MED) is the most promising method, as it presents low energy consumption compared to the most used methods, due to the potential for self-sufficiency of the thermal energy required and because pretreatment is not necessary as complex, since its operation takes place at a moderate temperature. Subsequently, a case study was carried out, involving mathematical modeling and numerical simulation of a MED desalination plant, using the Engineering Equation Solver (EES) software. Finally, the parametric analysis was carried out, which showed that the model used for the case study presents a good performance, in addition to being adaptable for implementation in a series of
\end{abstract}


possibilities. In this way, case studies in the area can lead to practical models that can meet existing demands, as well as the adaptation of methods such as the one in question.

Keywords: Desalination; MED; EES.

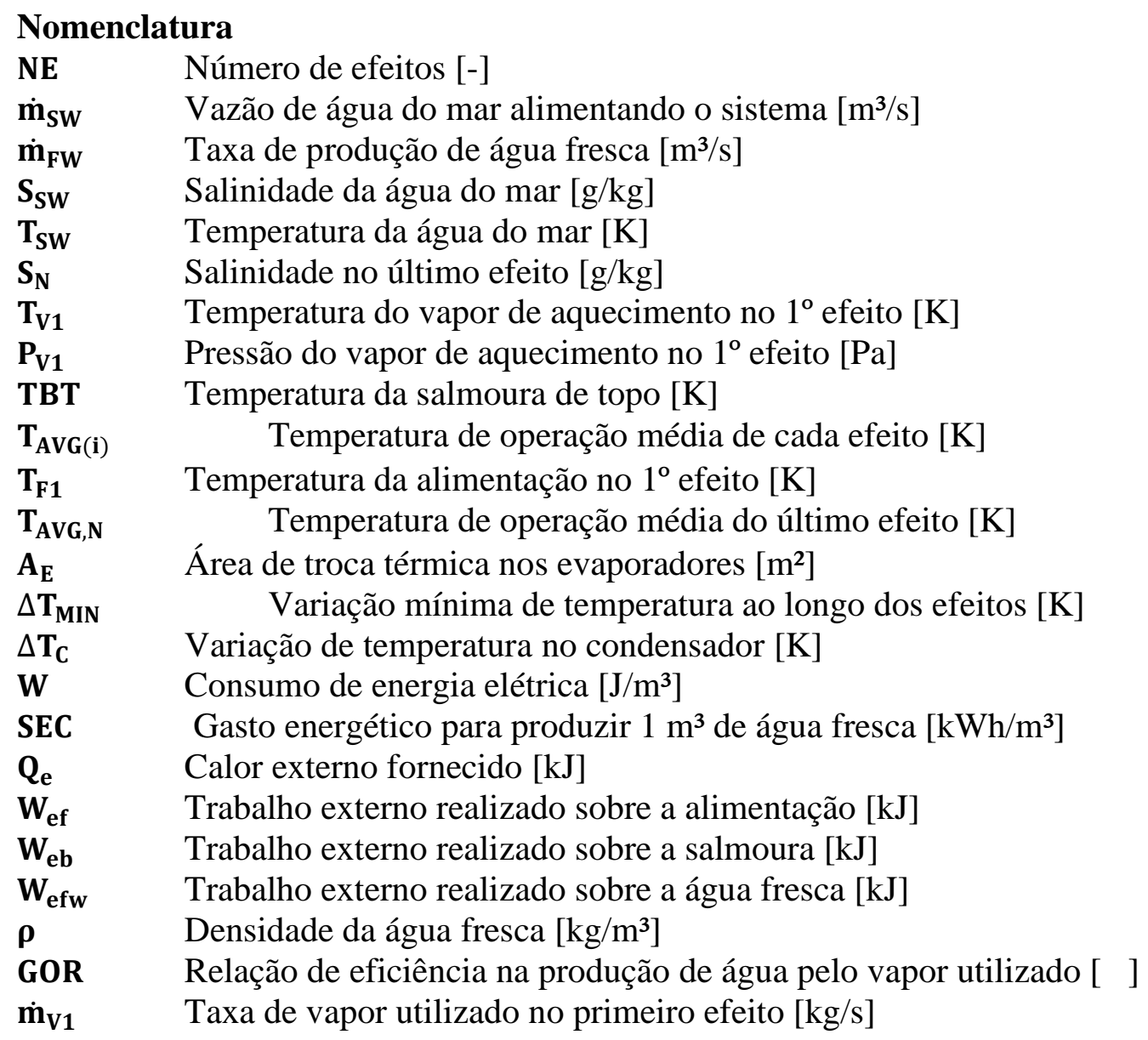

\section{Introdução}

A água é essencial para a vida na Terra. É ela que possibilita vida animal e vegetal. Como agente da intempérie é responsável por modificação de relevos e paisagens, além de constituir rios, mares e lagos. De toda água presente no planeta cerca de $97 \%$ encontra-se nos oceanos, sendo os outros $3 \%$ água doce, dos quais $2 \%$ constituem geleiras e calotas polares e somente $1 \%$ encontra-se em rios, lagos e aquíferos subterrâneos [1].

Aproximadamente $13 \%$ da água doce presente no planeta encontra-se no Brasil, contudo estima-se que $17 \%$ da sua população não tem acesso à água potável, sendo esse número mais agravante em algumas regiões, como a região Nordeste. Não obstante, apesar da abundância, sua escassez tem sido ocasionada em outras regiões por fatores naturais, como taxa pluviométrica reduzida, aquecimento global e efeito estufa, bem como pela gestão errônea dos recursos hídricos [2, $3]$.

Em virtude disso, têm-se discutido a respeito de meios de produzir água potável a partir da dessalinização da água do mar [4, 5]. No Brasil, o Programa Água Doce, introduzido pelo Governo Federal em 2004, é responsável pela difusão da dessalinização no país, sendo que, segundo dados do Ministério do Meio Ambiente, 94.340 pessoas recebem água potável proveniente de 150 dessalinizadores espalhados por todo o país.

Processos de dessalinização já são utilizados sobretudo em países com altos índices de águas salinas ou regiões desérticas, compreende a um processo de separação com o intuito de remover o excedente de sais minerais presentes na água. E esses são classificados em relação à formação de fase e em relação à fonte de energias requerida pelo processo [6, 7]. 
Nota-se, portanto, a necessidade de dominar a engenharia dos processos de dessalinização para conseguir torná-los mais economicamente vantajosos e passíveis de serem realizados em maior escala. A simulação é uma área da engenharia que flexibiliza a manipulação e validação de variáveis em curto espaço de tempo, possibilitando o domínio prévio do escopo do processo facilitando seu planejamento operacional [8].

A idealização desse trabalho surgiu de uma demanda da Prefeitura de Fortaleza-CE de projetos de dessalinização de água do mar para abastecer a cidade $1 \mathrm{~m}^{3} / \mathrm{s}$ de água doce, sendo a salinidade de seu mar em torno de $37 \mathrm{~g} / \mathrm{kg}$ e temperatura da água máxima de $28,6^{\circ} \mathrm{C}$. Dessa forma, inicialmente esse trabalho visou identificar nos diferentes métodos de dessalinização o que melhor atendesse a Fortaleza, levando em consideração potencial produtivo, consumo de energia e pré-tratamentos requeridos $[11,12,13]$.

Ademais, o objetivo desse trabalho engloba explorar na forma de uma revisão bibliográfica os princípios de funcionamento de diferentes processos de dessalinização, suas capacidades produtivas e requerimento energético. Diante desses dados, o MED foi adotado para realização de um estudo de caso, partindo da verificação da sua modelagem matemática e seguinte reprodução de um caso real utilizando o software Engineering Equation Solver (EES).

\section{Método Proposto}

A parte inicial do presente estudo constitui-se de uma revisão na literatura realizada com a finalidade de atualizar o estado da arte de processos de dessalinização de água do mar. A pesquisa foi realizada utilizando-se de periódicos, revistas, teses e dissertações. Um levantamento do estado da arte de 31 anos, com a maior coleta de dados quanto possível.

O estudo apresentou também a escolha de uma metodologia para estudo de caso, a Destilação por Múltiplo Efeito, do inglês Multi-Effect Distillation (MED). Para o estudo de caso citado, embasou-se na modelagem matemática desenvolvida por Barraza [14]. Assim como o autor em questão, adotou-se o software Engineering Equation Solver (EES) para a realização de uma análise paramétrica de algumas variáveis do processo.

Por fim, o estudo apresenta a importância da aplicação dessas tecnologias no contexto energético atual e na crise hídrica. Considerando as crescentes demandas atuais, apresenta também a possibilidade de implementação de tais tecnologias no Nordeste brasileiro, principalmente. Além de uma breve análise econômica.

\section{Estado da Arte}

Os processos de dessalinização classificam-se em relação à formação de fase e em relação à fonte de energias requerida pelo processo. Quanto à formação de fase o processo é classificado como térmicos (ocorre mudança de fase) ou de separação por membrana (não ocorre mudança de fase). Já em relação à energia requerida pelo processo, esta pode ser oriunda de fonte térmica, mecânica ou elétrica, a Figura 1 apresenta um diagrama contendo tal classificação [6, 7]. 


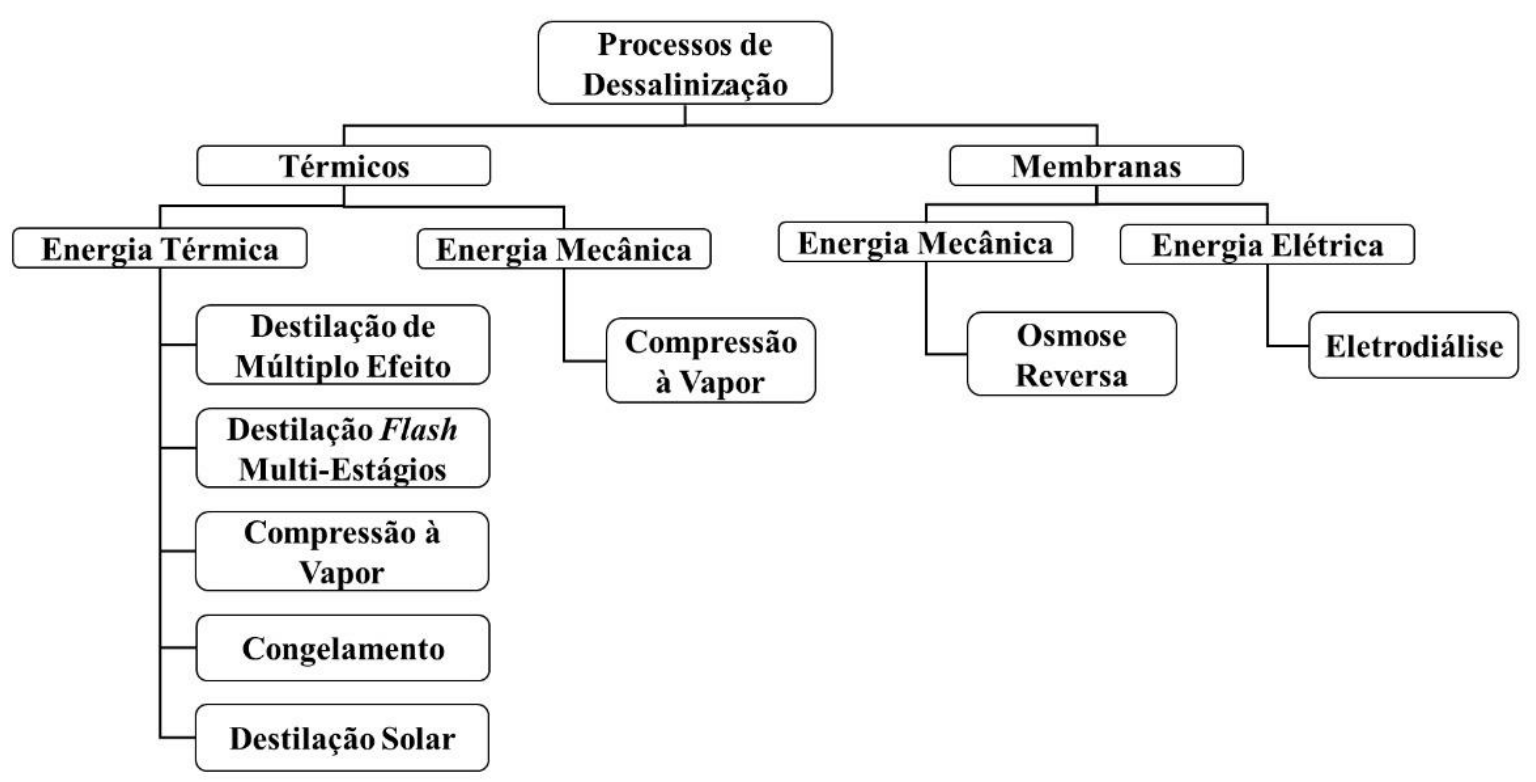

Figura 1: Diagrama contendo a classificação dos processos de dessalinização.

Nos processos térmicos as correntes de saída consistem em duas correntes aquosas, uma de baixa concentração de sais (permeado) e outra altamente concentrada (salmoura concentrada). Nesse tipo de processo a separação é viabilizada ao ser fornecida uma fonte de calor para que a água evapore. Sendo que os processos térmicos mais utilizados são a destilação flash de múltiplos-estágios e a destilação de múltiplo efeito. Seguidos pelo processo de compressão a vapor, congelamento e evaporação solar. O custo energético requerido para manter a água congelada faz com que seja menos utilizado que os já citados. Já a evaporação solar é um método econômico e sustentável de dessalinização, contudo requer ambientes sujeitos a alta irradiação solar [01, 07].

Nos processos de separação por membrana, as correntes de saída na osmose reversa também consistem em duas correntes aquosas, uma de baixa concentração de sais (permeado) e outra altamente concentrada (rejeito salino). Entretanto, na eletrodiálise são retiradas três correntes, a de permeado e as duas correntes de rejeito, uma contendo os ânions e outra contendo os cátions [01, 06].

A partir de agora, será tratado da produção de água fresca por diversos processos. Entende-se por água fresca aquela que sai do processo produtivo, porém ainda não se encontra potável. A seguir, apresentam-se os processos com base na divisão por energia principal requerida.

\subsection{Energia Elétrica}

\subsubsection{Eletrodiálise (ED)}

A eletrodiálise é um processo de separação eletroquímico que utiliza do potencial elétrico como força eletromotriz para deslocar seletivamente os sais através de uma membrana, deixando para trás água doce. Sua unidade consiste em um sistema de pré-tratamento, pilha de membrana, bomba de circulação de baixa pressão, fonte de alimentação de corrente contínua e um sistema de póstratamento, conforme exposto pela Figura $2[09,10]$. 


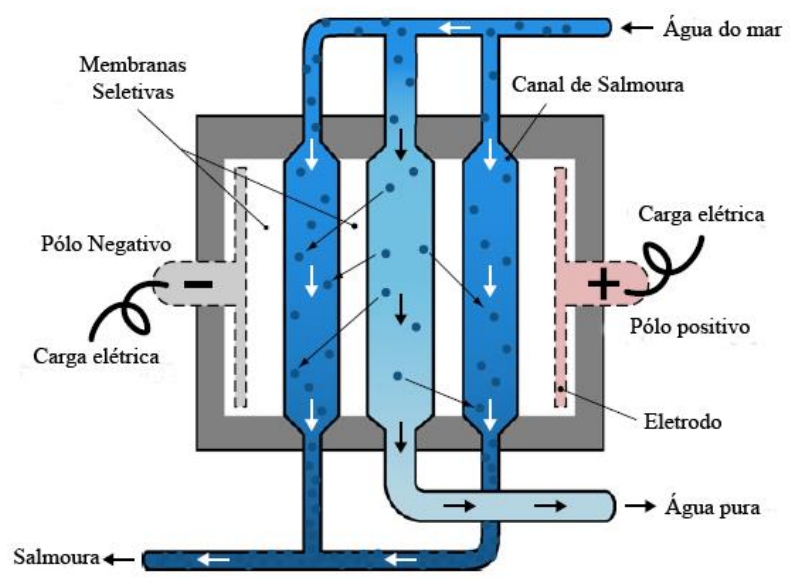

Figura 2: Diagrama esquemático de uma unidade de RO. Fonte: Adaptado de [09].

Nesse método eletrodos são conectados a uma fonte externa de corrente contínua, e ao recipiente de água salgada que contém a membrana seletiva de íons conectada em paralelo para formar canais. A água salobra flui por esses canais com os eletrodos eletricamente carregados, fazendo com que íons sal positivos atravessem a membrana permeável a cátions em direção aos eletrodos negativos, e os íons sal negativos atravessem a membrana permeável aos ânions em direção ao eletrodo positivo, o que resulta na remoção de salinidade da água. A capacidade de uma planta de ED varia de 2 a 145.000 $\mathrm{m}^{3} / \mathrm{dia}$, seu requerimento de energia é apenas elétrico, na faixa de 2,64 a 5,5 $\mathrm{kW} \mathrm{h} / \mathrm{m}^{3}[15,19,20,23$, $24,25]$.

\subsection{Energia Mecânica}

\subsubsection{Osmose Reversa (RO)}

A osmose é um processo que tem o potencial químico como força eletromotriz. Tratando-se da passagem de água do meio menos concentrado para o mais concentrado, assim igualando o potencial químico. A diferença para a osmose é reversa é que nesse último caso, ela ocorre em sentido inverso, passando a água do meio mais concentrado para o menos concentrado.

$\mathrm{Na}$ osmose reversa o escoamento da água é o inverso ao da osmose. Ela se baseia numa filtração pressurizada em que o filtro é uma membrana semipermeável que permite a passagem de água, mas não de sal. Dessa forma, água salina é bombeada para um recipiente fechado, onde então é pressurizada através da membrana, parte da água atravessa a membrana e a água remanescente tem sua concentração de sal aumentada [09, 10].

Essa técnica de dessalinização possui quatro subsistemas: pré-tratamento, bomba de alta pressão, membrana e pós-tratamento, conforme exposto pela Figura 3. Sendo que o pré-tratamento é importante porque a água deverá fluir através de passagens muito estreitas, sendo necessário remover os sólidos suspensos e para evitar precipitação de sal ou crescimento microalgal. Já o pós-tratamento remove gases e corrige o $\mathrm{pH}[09,10]$. 


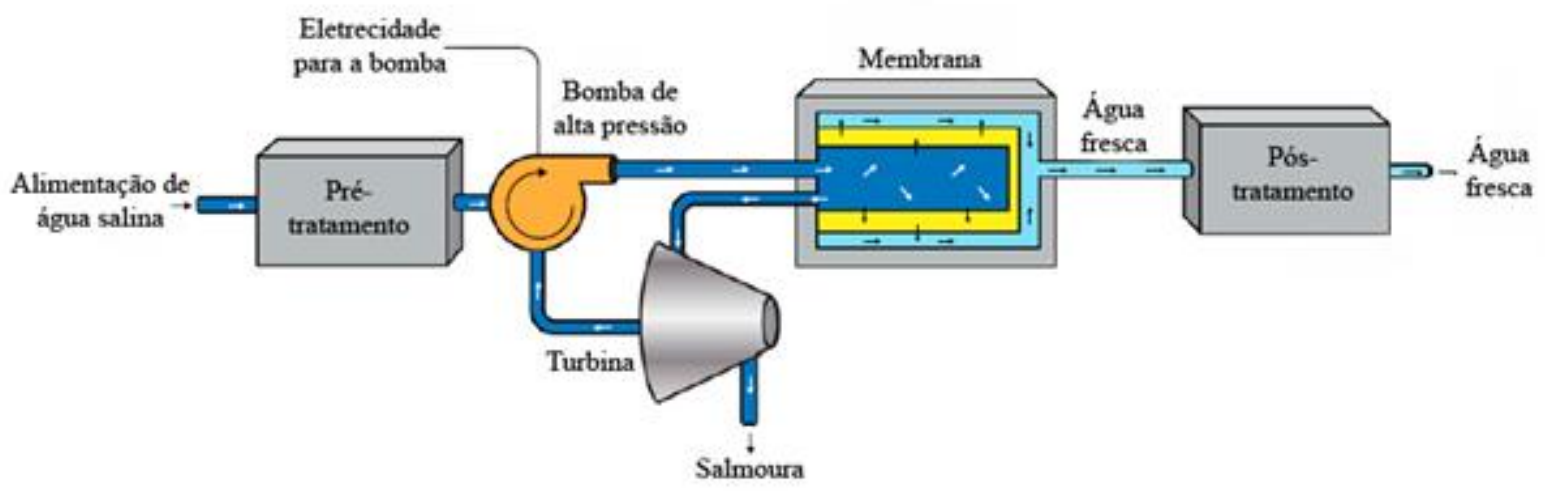

Figura 3: Diagrama esquemático de uma unidade de RO. Fonte: Adaptado de [09].

Essa é a técnica de dessalinização mais utilizada. Apresenta capacidade instalada entre 0,1 $\mathrm{m}^{3} /$ dia (aplicações marítimas e domésticas) e acima de $128.000 \mathrm{~m}^{3} /$ dia (aplicações comerciais), seu requerimento de energia é apenas elétrica, incluso na faixa de 4 a $6 \mathrm{~kW} \mathrm{~h} / \mathrm{m}^{3}[15,19,20,21,22]$.

\subsubsection{Destilação por Compressão Mecânica à Vapor}

A destilação por compressão a vapor é uma técnica utilizada em escalas pequena e média. Seu princípio de funcionamento assemelha-se ao MED, contudo nesse caso baseia-se na compressão do vapor de água gerada a altas pressões. Sendo que existem duas formas de operação distintas, uma em que a compressão do vapor é feita por meio de um compressor mecânico utilizando eletricidade (MVC). A MVC é efetuada em apenas uma etapa [09, 11].

As plantas que utilizam a compressão a vapor tiram vantagem do princípio da redução da temperatura do ponto de ebulição por meio da redução da pressão. E essa capacidade de trabalhar com temperaturas mais baixas ajuda a diminuir os efeitos da corrosão [10,11].

A salmoura concentrada é removida do vaso evaporador pela bomba de salmoura concentrada. Essa corrente é dividida, uma porção é misturada com a alimentação de entrada e a restante é bombeada para descarte. A capacidade do MVC varia entre 100 e $3.000 \mathrm{~m}^{3} / \mathrm{dia}$, seu requerimento de energia é apenas elétrica, incluso na faixa de 7 a $12 \mathrm{~kW} \mathrm{~h} / \mathrm{m}^{3}[15,19,20]$.

\subsection{Energia Térmica}

\subsubsection{Destilação por Compressão Térmica à Vapor}

Esse método possui algumas diferenças se comparado ao método de compressão mecânica. Nesse caso, a compressão térmica adiciona pequenas quantidades de vapor a alta pressão por meio de ejetor (TVC) e necessita de mais de uma etapa $[09,11]$.

Por sua vez, a capacidade do TVC varia entre 10.000 e $30.000 \mathrm{~m}^{3} /$ dia e seu consumo total de energia elétrica (energia elétrica acrescida da energia térmica equivalente) encontra-se em torno de $16,26 \mathrm{~kW} \mathrm{~h} / \mathrm{m}^{3}[15,19,20]$. A Figura 4 esquematiza tanto o MVC quanto o TVC. 


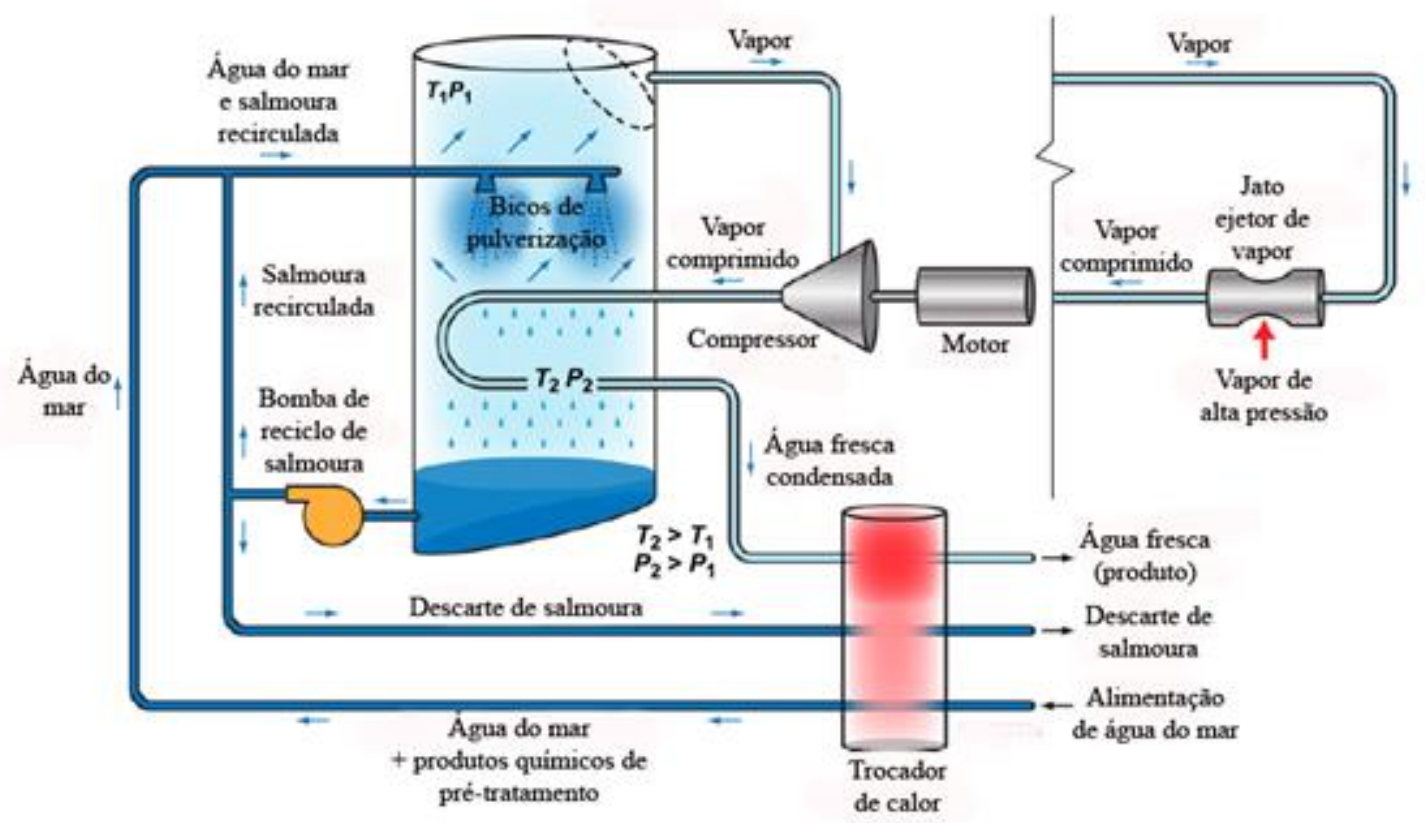

Figura 4: Diagrama esquemático de unidades de MVC e TVC, respectivamente. Fonte: Adaptado de [09].

\subsubsection{Destilação por Congelamento}

Na formação dos cristais de gelo os sais dissolvidos são excluídos naturalmente, portanto, antes de toda a massa ser descongelada a mistura é lavada e enxaguada para remover os sais. O gelo então é derretido para produzir água doce. Essa técnica apresenta como vantagens perante às outras o potencial mínimo para corrosão e pouca incrustação. Sendo que o processo pode ser direto ou indireto. No congelamento direto a água é seu próprio refrigerante, já no indireto é utilizado um líquido volátil insolúvel em água. $\mathrm{O}$ custo energético requerido para manter a água congelada faz com que seja menos utilizado $[07,10]$.

\subsubsection{Destilação Solar}

A destilação solar é basicamente um grande tanque com uma cobertura transparente, que utiliza da entrada de radiação solar para aumentar a temperatura da água salgada. A exposição ao sol faz com que a água evapore e condense ao tocar a parte interior da cobertura, escorrendo e sendo recolhida lateralmente por uma calha que conduz a água destilada para fora da cobertura. A Figura 5 ilustra um sistema de destilação solar [10, 11].

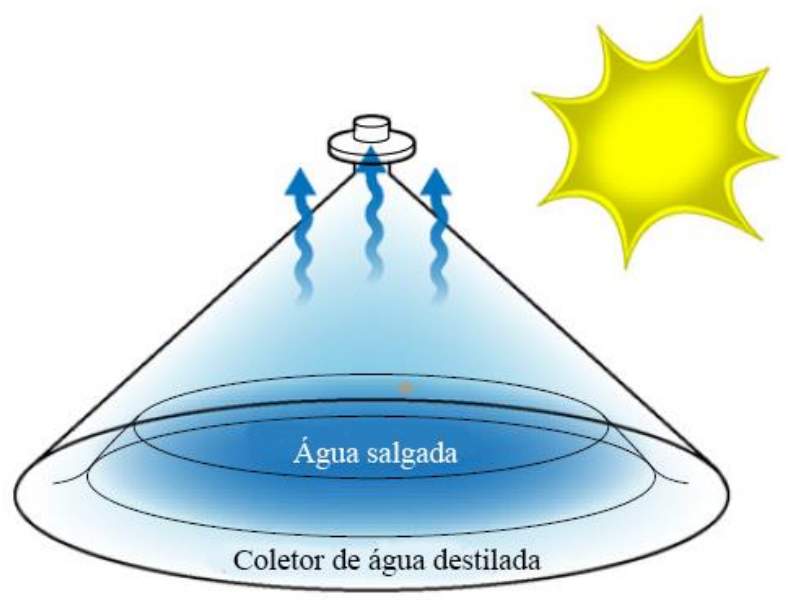

Figura 5: Diagrama esquemático de uma unidade de destilação solar. Fonte: Adaptado de [09]. 
Essa técnica apresenta baixos custos energéticos. Contudo, está sujeita às condições climáticas, que nem sempre são as mais favoráveis à realização do processo, além de requerer uma área de implantação muito grande. O que torna a técnica viável para regiões do globo com vastas áreas desertas e com baixos recursos técnicos e econômicos. Aplicações do processo na África e Índia possuem produções na faixa de 1,64 a 3,20 $\mathrm{m}^{3}$ de água por $\mathrm{m}^{2}$ de área implantada por dia $[10,11]$.

\subsubsection{Destilação Flash de múltiplos-estágios (MSF)}

O processo de destilação flash de múltiplos-estágios consiste num conjunto de câmaras sucessivas, que em seu interior ocorre vaporização instantânea ou flash.

Nesse processo água salgada fria começa a circular por um sistema de tubos que se encontram envoltos em vapor quente, aquecendo a água salgada ao longo de sua circulação. Então ao passar por esses tubos, a água entra numa caldeira de salmoura e em seguida entra ainda mais quente no primeiro estágio, onde a pressão é tal que a água ferve instantaneamente. $O$ vapor então condensa ao trocar calor com a água fria circulando através dos tubos, e precipita numa calha contida dentro do estágio, conduzindo a água doce para o fora do sistema. A salmoura restante segue para o segundo estágio, onde a temperatura de operação é sempre inferior à anterior, diminuição esta devido à diminuição da pressão entre fases consecutivas $[10,11]$. O processo se repete em todos os estágios seguintes, conforme exposto pela Figura 6.

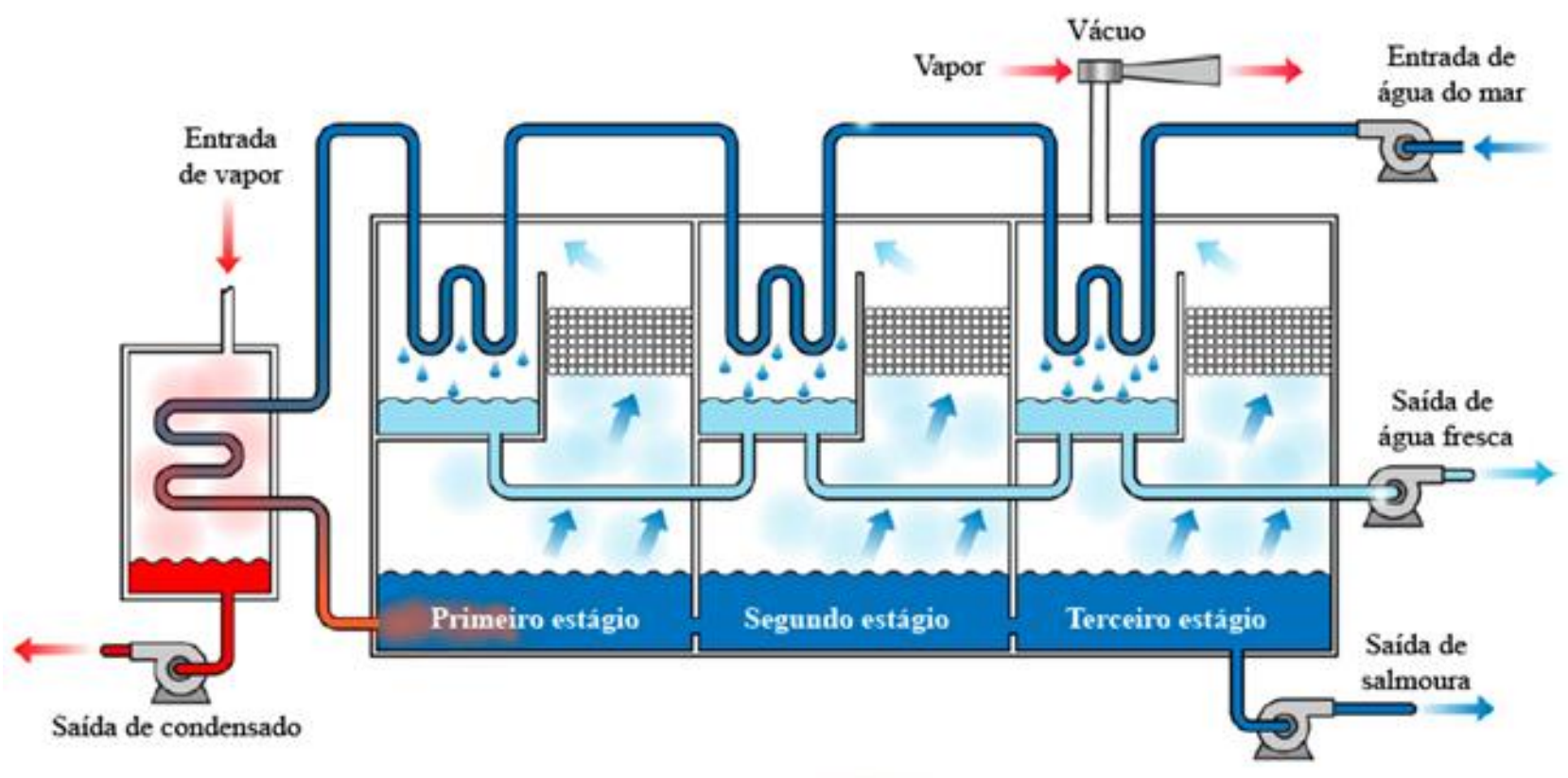

Figura 6: Diagrama esquemático de uma unidade de MSF. Fonte: Adaptado de [09].

O processo MSF que requer energia térmica na forma de vapor de baixa pressão (1 a 3 bar) para o aquecimento da salmoura, vapor de média pressão para os ejetores gerarem vácuo necessário em diferentes seções da unidade, e energia elétrica para acionar várias bombas da unidade. As unidades de MSF geralmente variam de 10.000 a $70.000 \mathrm{~m} 3 /$ dia, e a quantidade de estágio varia de 4 a 40 cada. Seu consumo total de energia elétrica (energia elétrica acrescida da energia térmica equivalente) encontra-se na faixa de 19,58 a $27,25 \mathrm{~kW} \mathrm{~h} / \mathrm{m}^{3}[09,15,16,17,18,19,20]$.

A vaporização instantânea (flash) forma escamas e depósitos nos tubos, tornando a limpeza e remoção periódicas necessárias. MSF é atualmente o segundo processo de dessalinização mais instalado em todo o mundo após o processo de Osmose Reversa [09].

\subsubsection{DESTILAÇÃo DE MúltiPLo EFeITO (MED)}

O processo de destilação de múltiplo efeito começa com a aspersão da água salgada fria sobre um conjunto de tubos quentes, parte da água evapora e segue para fornecer calor para o segundo efeito. Já a água que não evapora cai no fundo e é bombeada para o segundo efeito, iniciando o segundo ciclo do processo MED. O processo se repete em cada novo efeito. Assim como o processo 
MSF, a pressão e a temperatura vão diminuindo ao longo dos efeitos. Calor externo é fornecido para aumentar a temperatura da salmoura do primeiro efeito [09], [11]. A Figura 7 apresenta um diagrama esquemático de uma unidade de MED.

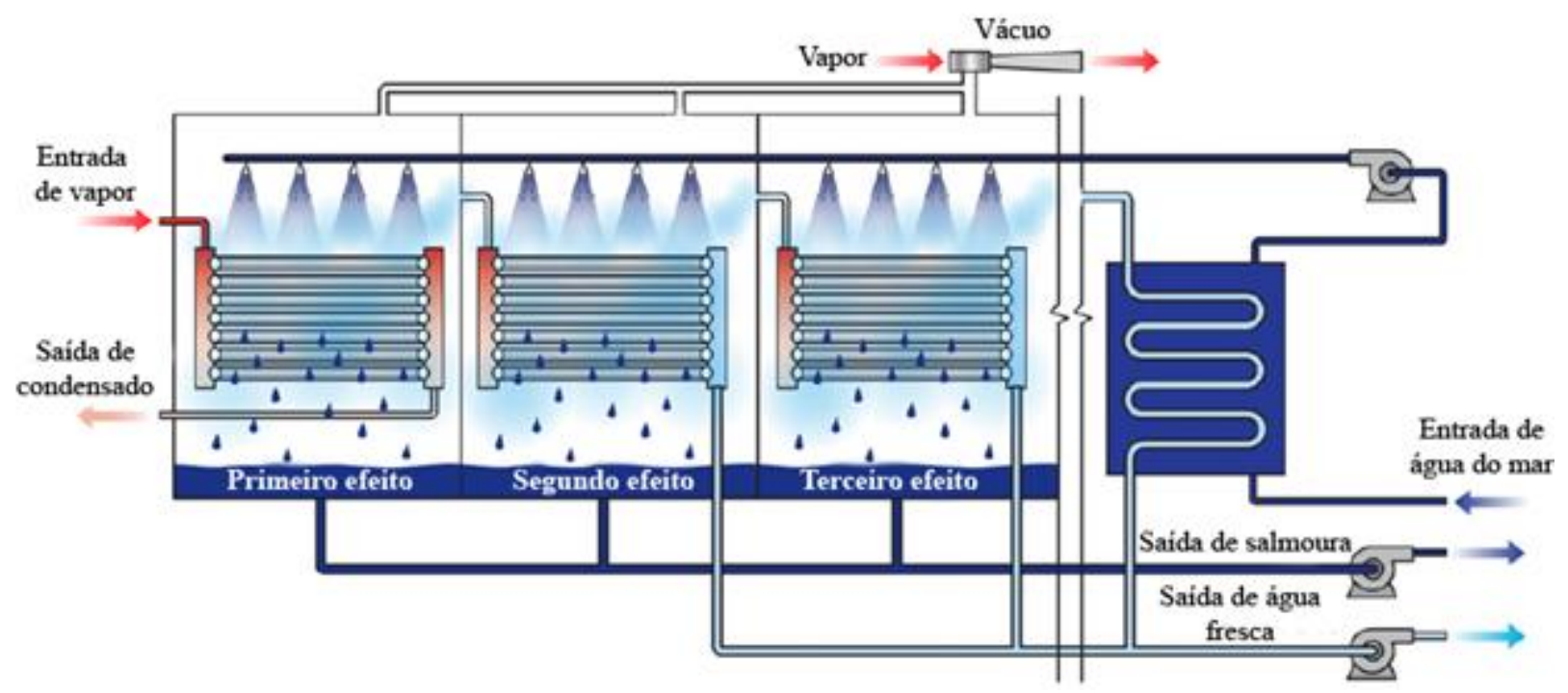

Figura 7: Diagrama esquemático de uma unidade de MED. Fonte: Adaptado de [09].

Nas grandes plantas geralmente encontra-se de 6 a 16 efeitos, sendo construídas com capacidades de 600 a $30.000 \mathrm{~m}^{3} / \mathrm{dia}$. Seu consumo total de energia elétrica (energia elétrica acrescida da energia térmica equivalente) encontra-se na faixa de 14,45 a $21,35 \mathrm{~kW} \mathrm{~h} / \mathrm{m}^{3}$, sendo praticamente autossuficiente em termos de produção de energia térmica, suprindo a demanda requerida. Nos últimos anos, o interesse pelo processo MED foi renovado e tendo ganhado participação de mercado [10], [15], [19], [20].

Assim como o MSF, o MED adapta-se a qualquer tipo de fonte de calor, além de possuir uma capacidade para dessalinizar grandes quantidades de água salgada. É um método com baixo consumo elétrico, se comparado aos outros mais usados (Osmose Reversa e MSF). Ademais a temperatura de funcionamento é baixa, o que evita grande corrosão e não necessita de um pré-tratamento da água salgada tão complexo como o requerido pelos outros métodos. Não obstante, é uma técnica que funciona melhor anexada a uma central elétrica, o que limita sua instalação [09], [11].

\section{Estudo de Caso}

\subsection{Destilação de Múltiplo Efeito}

O método de dessalinização MED foi identificado como promissor para prosseguimento do trabalho pela adaptabilidade a variadas fontes de calor e capacidade de produção de grandes quantidades de água (englobando a faixa requerida pela demanda de Fortaleza-CE). Sendo o MED vantajoso pelo baixo consumo de energia se comparado aos métodos mais utilizados (Osmose Reversa e MSF), pela potencialidade de autossuficiência da energia térmica requerida e por não ser necessário um pré-tratamento tão complexo por operar a uma temperatura moderada.

Uma planta de MED comumente opera em Alimentação Direta (Forward Feed-FF) ou Alimentação Paralela (Parallel Feed-PF). Para a FF a água salobra é alimentada no primeiro efeito e a salmoura concentrada alimenta o efeito seguinte, e assim sucessivamente. Já para a PF, a água do mar é alimentada diretamente em todos os efeitos [27, 29].

Além dos evaporadores, para favorecer a eficiência energética, as plantas contam com préaquecedores, tanques-flash e condensador. As figuras 8 e 9 trazem diagramas esquemáticos apresentando os diferentes tipos de alimentação e os componentes da planta. 


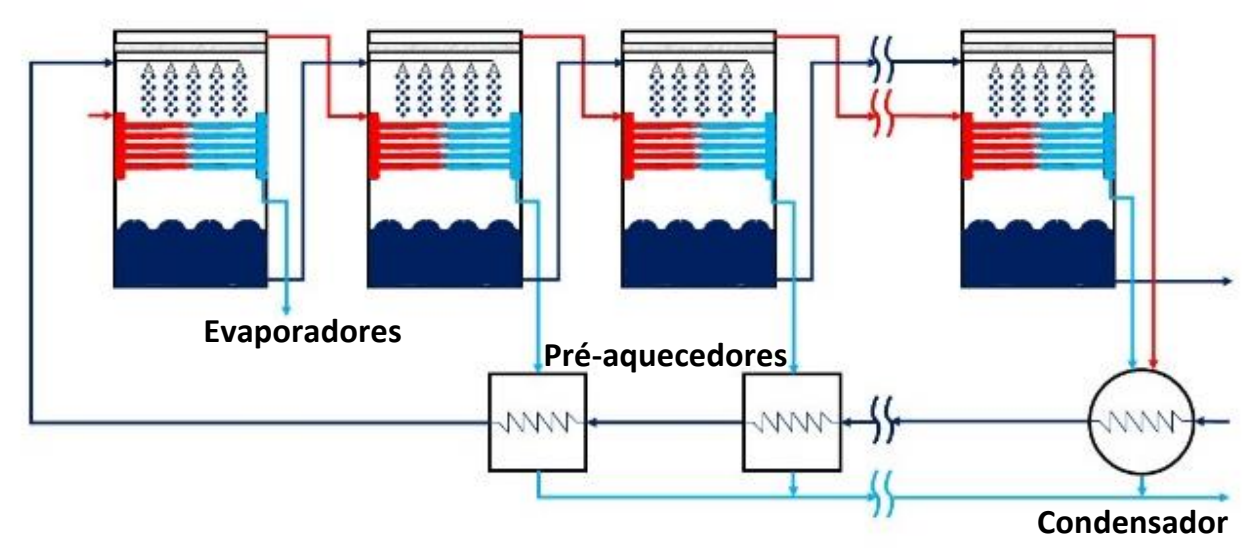

Figura 8: Diagrama esquemático de uma unidade de MED com alimentação direta (FF).

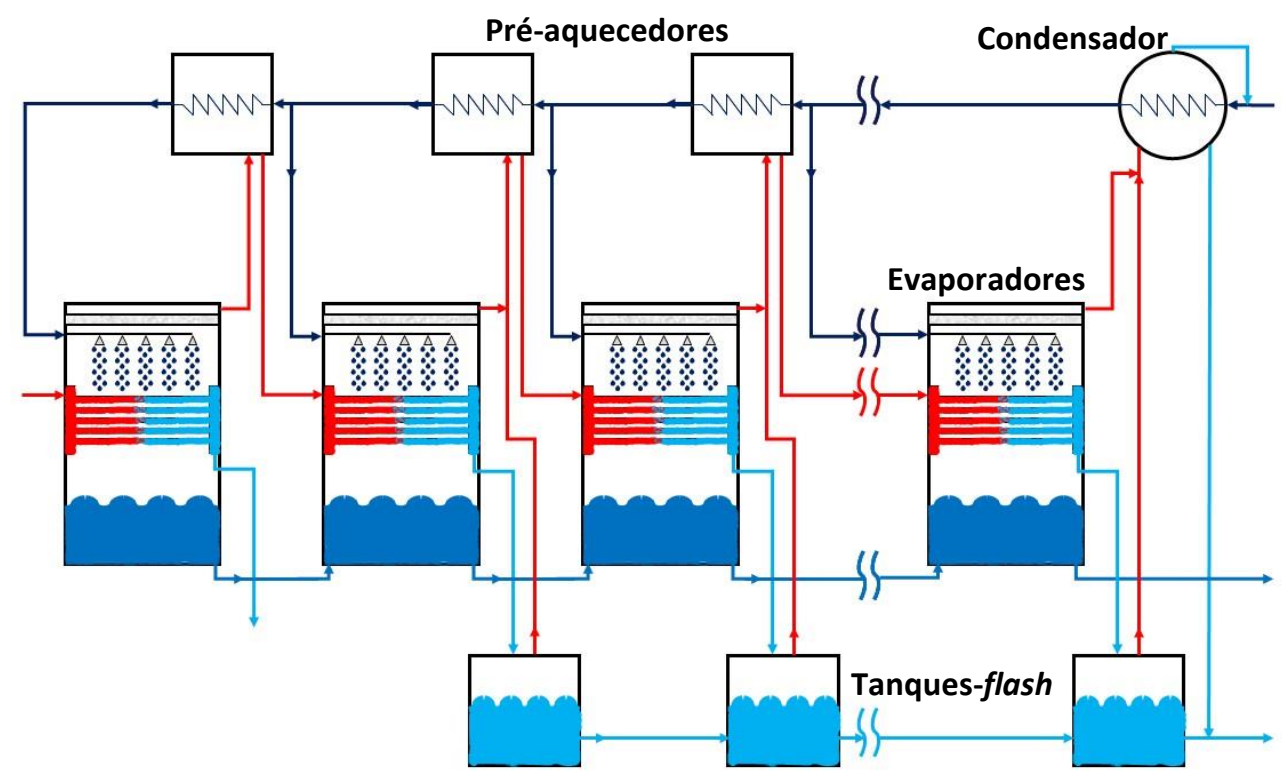

Figura 9: Diagrama esquemático de uma unidade de MED com alimentação paralela (PF).

Foram coletados diferentes dados operacionais de diferentes plantas de MED encontradas na literatura, sendo apresentados nas tabelas 1 e 2 . 
Tabela 1: Dados operacionais de diferentes MEDs.

\begin{tabular}{|c|c|c|c|c|c|c|c|c|c|c|c|c|c|c|c|c|}
\hline \multirow{2}{*}{ Fonte } & \multicolumn{16}{|c|}{ Variável } \\
\hline & NE & $\dot{\mathbf{m}}_{\mathrm{SW}}$ & $\dot{\mathbf{m}}_{\mathrm{FW}}$ & $\mathbf{S}_{\text {SW }}$ & $\mathbf{T}_{\text {SW }}$ & $\mathbf{S}_{\mathrm{N}}$ & $\mathrm{T}_{\mathrm{V} 1}$ & $\mathbf{P}_{\mathrm{V} 1}$ & TBT & $\mathbf{T}_{\mathrm{AVG}(\mathrm{i})}$ & $\mathrm{T}_{\mathrm{F} 1}$ & $\mathrm{~T}_{\mathrm{AVG}, \mathbf{N}}$ & $\mathbf{A}_{\mathbf{E}}$ & $\Delta \mathbf{T}_{\text {MIN }}$ & $\Delta \mathbf{T}_{\mathbf{C}}$ & $\mathbf{W}$ \\
\hline [17] & 4 & & $\begin{array}{c}5,276 \\
\cdot 10^{-2}\end{array}$ & & & & 336,15 & $\begin{array}{l}1,5 \\
\cdot 10^{6}\end{array}$ & 319,15 & $\begin{array}{c}331,15 a \\
319,15\end{array}$ & & & & & & \\
\hline [21] & $4 a 22$ & & & & & & & & $\begin{array}{c}328,15 a \\
358,15\end{array}$ & & & & & & & \\
\hline$[26]$ & - & & 3,472 & & & & & & & & & & & & & \\
\hline [27] & 10 & $\begin{array}{c}5,208 \\
\cdot 10^{-2}\end{array}$ & $\begin{array}{c}4,630 \\
\cdot 10^{-2}\end{array}$ & & 298,15 & & 353,15 & $\begin{array}{c}3,1 \\
10^{4}\end{array}$ & & & & & & & & \\
\hline [28] & 12 & & $\begin{array}{c}1,898 \\
\cdot 10^{-1}\end{array}$ & 33 & 291,65 & & 343,15 & & & & & & $\begin{array}{l}1,2 \\
\cdot 10^{5}\end{array}$ & & & \\
\hline [29] & 14 & $\begin{array}{c}3,900 \\
\cdot 10^{-1}\end{array}$ & $\begin{array}{r}5,787 \\
\cdot 10^{-1}\end{array}$ & 35 & 308,15 & & $\begin{array}{c}328,15 a \\
343,15\end{array}$ & $\begin{array}{c}3,1 \\
10^{4}\end{array}$ & & & & & & & & \\
\hline [30] & 6 & & $\begin{array}{c}9,530 \\
\cdot 10^{-4}\end{array}$ & 45 & & 70 & & & 342,15 & & & & & & & \\
\hline$[31]$ & 6 & & $\begin{array}{c}4,630 \\
\cdot 10^{-2}\end{array}$ & & & & & & & $\begin{array}{c}325,15 a \\
309,15\end{array}$ & 316,15 & & & & & \\
\hline [32] & 4 & & $\begin{array}{c}2,315 \\
\cdot 10^{-2}\end{array}$ & 45 & 308,15 & & & & & & 318,15 & & & & & \\
\hline [33] & 18 & $\begin{array}{c}1,003 \\
\cdot 10^{-2}\end{array}$ & $\begin{array}{c}1,389 \\
\cdot 10^{-3}\end{array}$ & & & & & & & & & & & & & \\
\hline
\end{tabular}




\begin{tabular}{|c|c|c|c|c|c|c|c|c|c|c|c|c|c|c|c|c|}
\hline$[34]$ & 8 & & $\begin{array}{c}1,003 \\
\cdot 10^{-3}\end{array}$ & 42 & 298,15 & & 343,15 & & & & & 313,15 & & 5 & 10 & \\
\hline$[35]$ & 11 & $\begin{array}{l}1,223 \\
\cdot 10^{-2}\end{array}$ & $\begin{array}{c}1,866 \\
\cdot 10^{-3}\end{array}$ & & 298,15 & & 343,05 & & 343,15 & $\begin{array}{c}340,85 a \\
310,75\end{array}$ & 314,55 & & & & & \\
\hline$[36]$ & 8 & $\begin{array}{c}5,015 \\
\cdot 10^{-3}\end{array}$ & $\begin{array}{l}2,417 \\
\cdot 10^{-3}\end{array}$ & 38 & 295,15 & 73 & 348,15 & & & & & & 62 & & & \\
\hline [37] & 8 & & $\begin{array}{c}3,472 \\
\cdot 10^{-1}\end{array}$ & & & & 343,15 & & 340,74 & & 308,15 & & & & & \\
\hline$[38]$ & 5 & & $\begin{array}{c}5,276 \\
\cdot 10^{-2}\end{array}$ & 46 & 298,15 & 69 & & & & & & 321,75 & & & & \\
\hline [39] & 18 & $8,33 \cdot 10^{-3}$ & & 34,48 & & & & & & & & & & & & \\
\hline$[40]$ & 14 & $\begin{array}{l}2,229 \\
\cdot 10^{-3}\end{array}$ & & 36 & 298,15 & 70 & 343,95 & & 342,15 & & 339,45 & & & & 7,3 & \\
\hline$[41]$ & $3 a r$ & & & 35 & 308,15 & 70 & 363,15 & & & & & & & & & $\begin{array}{l}5,4 \cdot 10^{6} \\
a 9 \cdot 10^{6}\end{array}$ \\
\hline$[42]$ & $4 a 6$ & & & 35 & 288,15 & 60 & & & 313,15 & & & & & 1,5 & 15 & $3,6 \cdot 10^{6}$ \\
\hline$[43]$ & - & & & 35 & 301,15 & 70 & $\begin{array}{c}338,45 a \\
368,15\end{array}$ & & 343,15 & & 311,15 & & & 3 & & \\
\hline$[44]$ & 20 & & & 45 & 300,15 & 70 & 390,15 & & & & & 312,35 & & & & \\
\hline$[45]$ & 11 & & & 42 & 298,15 & & & & & & & & & & & \\
\hline$[46]$ & $4 a 12$ & & & 46 & & & & $\begin{array}{c}2,5 \\
10^{6}\end{array}$ & & & 313,15 & & & & & \\
\hline
\end{tabular}




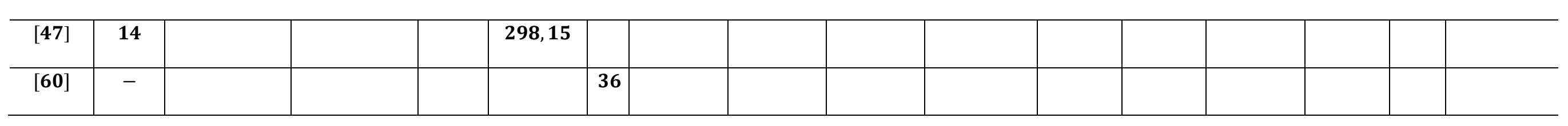


Tabela 2: Dados operacionais encontrados em apenas uma referência.

\begin{tabular}{|c|c|c|c|}
\hline Fonte & NE & Variável & \\
\hline$[\mathbf{3 1}]$ & 6 & Salinidade ao longo dos efeitos $[\mathrm{g} / \mathrm{kg}]$ & $40 ; 43 ; 45 ; 47 ; 49 ; 51$ \\
\hline$[27]$ & 10 & Pressão de operação do $1^{\circ}$ efeito $[\mathrm{Pa}]$ & $3,0 \cdot 10^{4}$ \\
\hline$[27]$ & 10 & Pressão do efeito 2 até 10 [Pa] & $4.2 \cdot 10^{3}$ \\
\hline$[40]$ & 3 a 6 & BPE para todos os efeitos $[\mathrm{K}]$ & 0,8 \\
\hline$[27]$ & 10 & Temperatura da água fresca $[\mathrm{K}]$ & 303,15 \\
\hline$[28]$ & 12 & Coeficiente global de transferência de calor $(\mathrm{U})$ no $1^{\circ}$ efeito $\left[\mathrm{W} / \mathrm{m}^{2} . \mathrm{K}\right]$ & 2.400 \\
\hline$[28]$ & 12 & Redução de U ao longo dos efeitos & $5 \%$ \\
\hline$[29]$ & 14 & $\begin{array}{l}\text { Coeficiente global de transferência de calor }(\mathbf{U} \cdot \mathbf{A}) \text { nos pré-aquecedores } \\
{[\mathrm{W} / \mathrm{K}]}\end{array}$ & $2,4 \cdot 10^{6}$ \\
\hline$[29]$ & 14 & Coeficiente global de transferência de calor $(\mathbf{U} \cdot \mathbf{A})$ no condensador & 11.839 .000 \\
\hline$[44]$ & 20 & {$[\mathrm{~W} / \mathrm{K}]$} & 1.566.480 \\
\hline$[42]$ & - & Variação mínima da temperatura no $1^{\circ}$ efeito $[\mathrm{K}]$ & 2,5 \\
\hline [42] & - & Variação mínima da temperatura nos pré-aquecedores $[\mathrm{K}]$ & 5 \\
\hline
\end{tabular}

Hamed et al. [48] compararam uma planta de dessalinização de múltiplo efeito com compressão térmica à vapor (MED-TVC) com outra com compressão mecânica à vapor (MED-MVC), ambas de 4 efeitos, reportando que o MED-TVC era mais eficiente, com base nos critérios que serão apresentados posteriormente. El-Dessouky et al. [6], introduziram uma modelagem matemática mais robusta para um MED, concluindo em análise dos parâmetros operacionais que a eficiência calculada na relação entre a quantidade de vapor alimentando o primeiro efeito e a massa de água doce produzida independe da temperatura da salmoura de topo.

Aly e El-Figi [44] estudaram a performance de um MED-FF, reforçando a citada conclusão de El-Dessouky et al., contudo aferiram que essa eficiência é notavelmente dependente do número de efeitos. Bahar et al. [49] avaliou a performance de um MED-MVC, concluindo que a concentração da salmoura afeta a quantidade de água doce produzida.

Ophir e Lokiec [50] chegaram à conclusão de que o MED é termodinamicamente melhor que o MSF devido ao seu menor consumo energético. Darwish et al. [51] concluíram que no sistema MED é possível explorar baixas temperaturas na fonte de calor quando opera a uma temperatura de salmoura de topo reduzida e que uma variação na temperatura de operação menor que $2^{\circ} \mathrm{C}$ é suficiente para aumentar consideravelmente a área de transferência de calor requerida.

Darwish and Abdulrahim [52] desenvolveram um modelo para diferentes combinações de alimentação, e em todas elas ao aumentar o número de efeitos observou-se aumento na eficiência do modelo. Mistry et al. [34] demonstraram que a vantagem dos sistemas de cogeração relaciona-se com capacidade de produzir água e energia requerida a custos mais baixos. 


\subsection{Modelagem matemática}

\subsubsection{Modelo e parâmetros estabelecidos}

O método desenvolvido por Barraza [14] consiste em um sistema de MED de alimentação paralela, cuja modelagem matemática foi validada com experimentos realizados em uma planta localizada no país Bahrain. A modelagem em questão realizou um único estudo experimental para validação, resultando em poucos dados para entrada e variação.

O modelo em questão apresenta um condensador que opera como pré-aquecedor para o último efeito e também como um resfriador para a água fresca gerada, a fim de produzir uma água com temperatura menor, igual a $40^{\circ} \mathrm{C}$. São utilizados também de ejetores para fornecer vapor e, portanto, energia térmica para o primeiro evaporador do processo. Estes equipamentos são necessários para a operação do mesmo, tendo em vista a demanda energética para o start do processo e sua finalização.

Como é possível perceber na Figura 10, há quatro efeitos de evaporadores. Os dois efeitos iniciais foram divididos em dois evaporadores em paralelo, dividindo as correntes igualmente, onde os evaporadores operam em uníssono, cuja finalidade é de facilitar a implementação da planta, sendo meramente econômico esse fator, além de ampliar a eficiência de troca térmica, pois se aumenta a área de troca térmica que o processo exige.

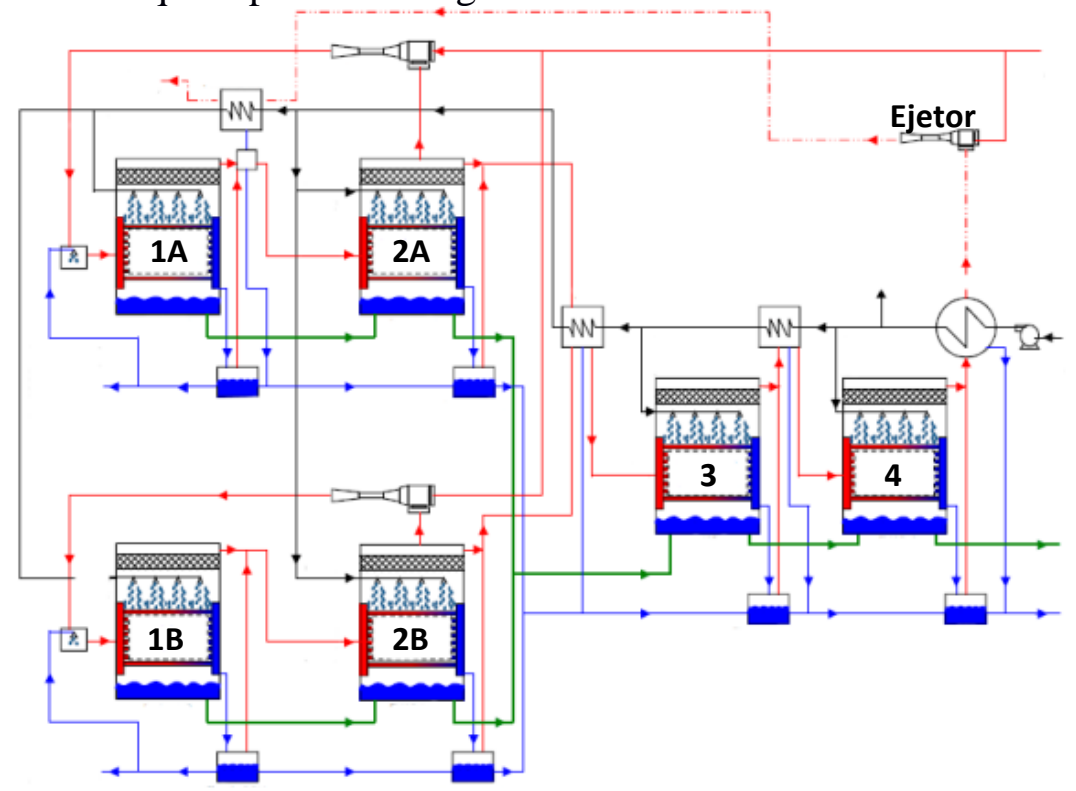

Figura 10: Modelo esquemático da planta adotada por Barraza. Adaptado de: [14].

Este estudo faz a análise do modelo e a interpretação da influência das variáveis no processo. As equações 1 e 2 foram utilizadas como critério de comparação de eficiência do processo.

$$
\begin{gathered}
\mathrm{SEC}=\frac{\mathrm{Q}_{\mathrm{e}}+\mathrm{W}_{\mathrm{ef}}+\mathrm{W}_{\mathrm{eb}}+\mathrm{W}_{\mathrm{efw}}}{\mathrm{m}_{\mathrm{fw}} / \rho} \\
\mathrm{GOR}=\frac{\mathrm{m}_{\mathrm{fw}}}{\mathrm{m}_{\mathrm{V} 1}}
\end{gathered}
$$


Sendo SEC estabelecido como o consumo específico de energia (Specific Energy Consumption), ou seja, a energia fornecida externamente ao sistema para gerar um metro cúbico de água fresca. Enquanto o GOR é definido como a taxa de ganho da saída (Gain Output Ratio), ou seja, a produção final de água em relação ao vapor fornecido no primeiro efeito de evaporadores. Ressalta-se que para a modelagem original realizada por Barraza [14], os valores de SEC e GOR foram, respectivamente, $98,1 \mathrm{kWh} / \mathrm{m}^{3}$ e 7,256 .

Em todas as análises realizadas, considerou-se uma mesma taxa de vapor fornecido externamente ao processo, desconsiderando a taxa de refluxo interna do processo, equivalente a $16,67 \mathrm{~kg} / \mathrm{s}$. Desta forma, o valor de GOR é ditado pela taxa de produção de água, assim como SEC, onde a energia fornecida externamente é praticamente constante.

Por conseguinte, conclui-se que o valor de SEC deve ser menor para que o processo seja otimizado, pois indica uma maior eficiência energética. Em contrapartida, espera-se um maior valor de GOR para um processo em melhores condições, pois indica, também um melhor aproveitamento energético do sistema. Para as análises realizadas, foram considerados os valores obtidos por Barraza [14] como referência.

\subsubsection{ANÁLISES PARAMÉTRICAS}

Para as análises realizadas, optou-se por considerar todos os valores de entrada do processo como constantes, enquanto foi feita a variação de apenas outra variável. Os valores utilizados como constantes para as análises paramétricas foram os mesmos que Barraza [14]. Para tal, escolheramse as seguintes variáveis operacionais:

- $\quad$ Massa de alimentação do processo $\left(\mathrm{m}_{\text {feed }}\right)\left[1,40.10^{6}\right.$ a $\left.1,53.10^{6} \mathrm{~kg} / \mathrm{h}\right]$;

- $\quad$ Salinidade da água de alimentação $\left(S_{\text {feed }}\right)[25$ a $41 \mathrm{~g} / \mathrm{kg}]$;

- Massa de resfriamento $\left(\mathrm{m}_{\mathrm{cool}}\right)$, que representa a massa que entra no processo em conjunto com a massa de alimentação, porém é descartada do sistema [470 a $650 \mathrm{~kg} / \mathrm{s}$ ];

- $\quad$ Relação entre as massas de alimentação nos diferentes evaporadores (Fm), que é uma relação estabelecida entre as massas que são inseridas nos primeiros evaporadores em relação aos últimos [1 a 6,5$]$

- $\quad$ Fator de incrustação, ou Fouling Factor (FF) $\left[0\right.$ a $\left.410^{-4} \mathrm{~m}^{2} .^{\circ} \mathrm{C} / \mathrm{W}\right]$.

Considerando as variáveis acima descritas, encontraram-se as seguintes relações gráficas. As figuras 11 a 15 mostram o comportamento de GOR e SEC para as variáveis descritas.

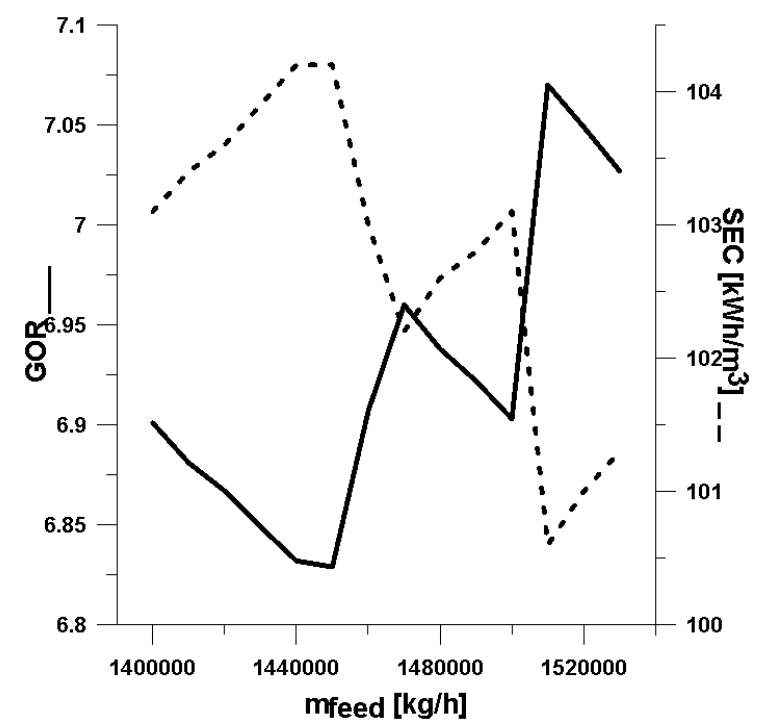

Figura 11: Efeito da massa de entrada no GOR e no SEC. 


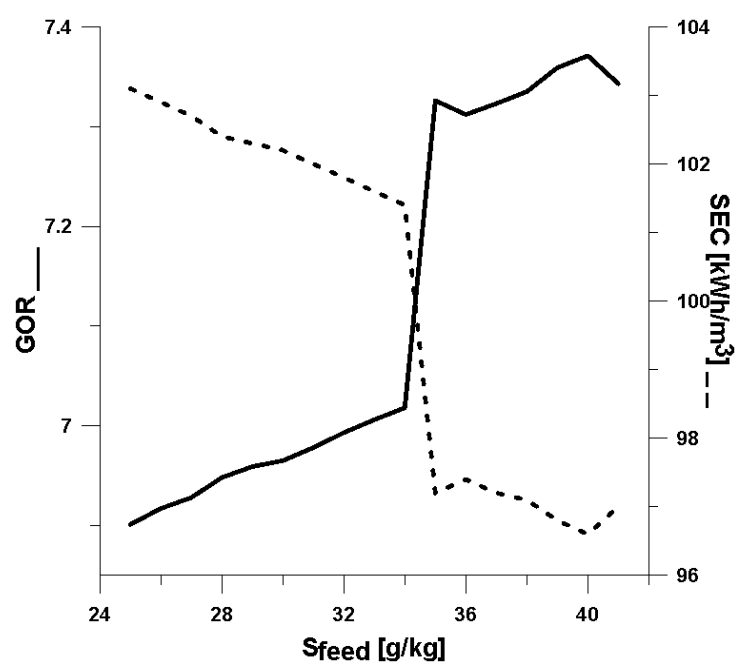

Figura 12: Efeito da salinidade de entrada no GOR e no SEC.

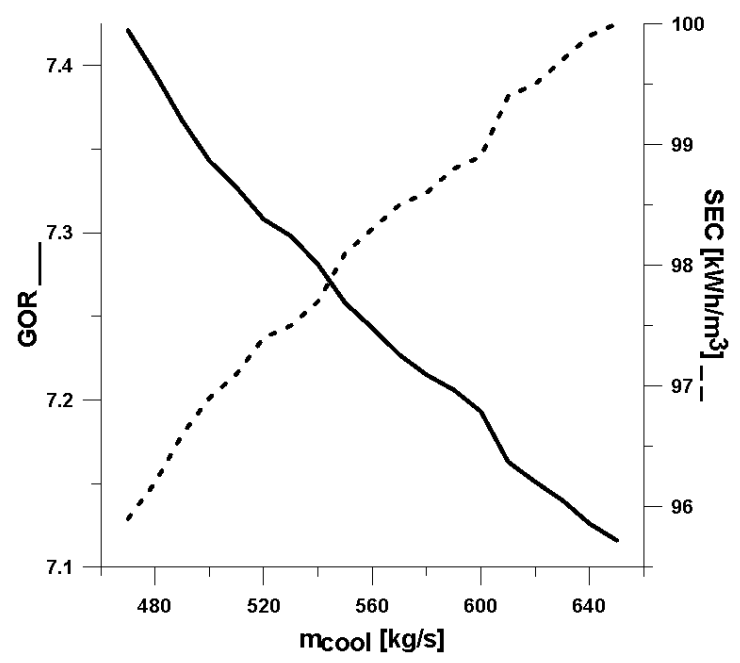

Figura 13: Efeito da massa de resfriamento no GOR e no SEC.

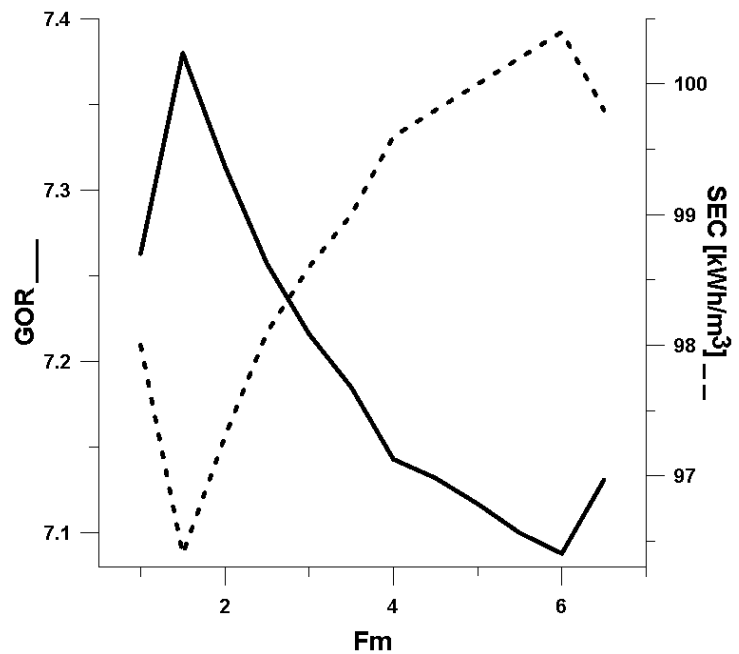

Figura 14: Efeito da relação entre as massas de entrada nos diferentes evaporadores no GOR e no SEC. 


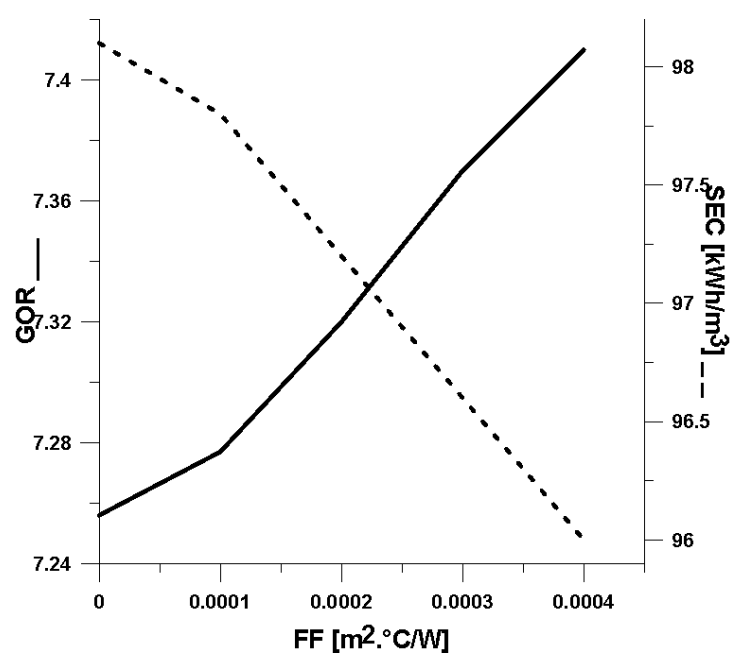

Figura 15: Efeito do fator de incrustação no GOR e no SEC.

Na Figura 11, percebe-se um comportamento anômalo de SEC e GOR com o aumento da massa de alimentação. Tal fato pode ser explicado com análises mais aprofundadas do processo, pois a planta em questão foi projetada para receber uma entrada de $1,4.10^{6} \mathrm{~kg} / \mathrm{h}$. Apesar de sua produtividade apresentar uma tendência crescente, há diversos pontos que não apresentam este comportamento, em função da não adequação ao sistema em questão. Como trabalhos futuros, é importante estudar as possibilidades de adaptação da planta para os encargos necessários do sistema. Realizando outras análises paramétricas para tentar adaptar melhor o sistema às condições desejadas, ou mesmo a possibilidade de ampliação do sistema em número de efeitos.

Para a faixa analisada, encontrou-se o ponto ótimo de operação com uma alimentação igual a $1,51.10^{6}$, obtendo um GOR igual a 7,070 e um SEC igual a $100,6 \mathrm{kWh} / \mathrm{m}^{3}$, encontrando uma operação menos eficiente que o modelo de Barraza [14].

Já na Figura 12, quando se analisa a salinidade, percebe-se uma tendência crescente da produção, ou seja, à medida que a salinidade da alimentação aumenta, é possível perceber com a análise do GOR e do SEC que a produção aumenta. Tal fato pode ser explicado termodinamicamente quando se analisa o sistema como uma sequência de evaporadores.

Ao adentrar o primeiro efeito, a água exige uma maior demanda energética para evaporar devido à sua elevação ebulioscópica, porém a produção neste efeito é menor. Contudo, o vapor gerado neste apresenta uma maior temperatura, aumentando a energia disponível para a evaporação nos efeitos seguintes e, por conseguinte, aumentando sua produção individual. Esse efeito em cadeia acaba gerando uma produção maior de água no sistema como um todo. Para a faixa analisada, obteve-se um ponto ótimo de operação com entrada de salinidade igual a $40 \mathrm{~g} / \mathrm{kg}$. Nesse ponto, obteve-se um GOR igual a 7,371 e um SEC igual a $96,6 \mathrm{kWh} / \mathrm{m}^{3}$, encontrando assim uma operação mais eficiente que Barraza [14].

A Figura 13 indica um decréscimo na produtividade do processo. Ao realizar uma análise da termodinâmica e da transferência de calor do processo, percebe-se que aumentar a quantidade de água de resfriamento indica uma maior massa para trocar calor como corrente fria no condensador. Logo, a massa que de fato alimentará os evaporadores receberá menos calor.

Termodinamicamente, esse processo prejudica a troca térmica nos evaporadores, pois a massa entrará mais fria nos mesmos, portanto terá uma maior demanda energética para atingir sua temperatura de saturação, dada a pressão de operação. Assim, ocorre um desgaste energético maior ao longo do processo, fazendo com que cada efeito produza, por consequência menos água.

A Figura 13 é um reflexo numérico desse esgotamento termodinâmico que ocorre.

Para a faixa analisada, obteve-se um ponto ótimo de operação com taxa de massa de resfriamento igual a $470 \mathrm{~kg} / \mathrm{s}$. Nesse ponto, obteve-se um GOR igual a 7,421 e um SEC igual a $95,9 \mathrm{kWh} / \mathrm{m}^{3}$, encontrando assim uma operação com maior eficiência que Barraza [14]. 
A Figura 14 traz a produtividade em relação à distribuição de massas entre os evaporadores. A relação de 1:1 mostra que ocorre uma sobrecarga nos evaporadores menores, ou seja, isso prejudica a produtividade, tendo em vista a capacidade dos mesmos ser menor em relação à troca térmica.

Há uma tendência de diminuição da produtividade, expressa tanto por GOR, quanto por SEC, à medida que essa relação aumenta, pois isso implica em uma maior massa sendo encaminhada para os evaporadores com maior capacidade de troca térmica. Pensando em um processo contínuo de alimentação paralela, encaminha-se um fluxo mássico grande do segundo para o terceiro efeito, dificultando a troca térmica com a água do mar de alimentação do mesmo efeito. Ou seja, esse processo prejudica a produtividade nos terceiro e quarto efeitos, de forma que represente um prejuízo expressivo à produtividade.

Para a faixa analisada, obteve-se um ponto ótimo de operação na proporção de 1,5:1 de massas, primeiro e segundo evaporadores em relação ao terceiro e quarto. Nesse ponto, obteve-se um GOR igual a 7,380 e um SEC igual a $98,0 \mathrm{kWh} / \mathrm{m}^{3}$, encontrando assim uma operação mais eficiente que Barraza [14].

Na Figura 15, analisa-se a variação do fator de incrustação. Entende-se incrustação como depósitos indesejáveis de sólidos em superfícies de troca térmica. Esses depósitos podem prejudicar a troca térmica, pois podem acarretar em corrosão da superfície. Esse coeficiente, para as temperaturas de operação apresenta para diferentes tipos de água, salobra, água do mar, ou mesmo água potável uma variação entre 0,0001205 e $0,000301 \mathrm{~m}^{2} .^{\circ} \mathrm{C} / \mathrm{W}$ [41]. Dessa forma, a escolha dos fatores para análise paramétrica, visou enquadrar-se nessa realidade.

Apesar disso, tal prejuízo só ocorre em longo prazo com depósitos maiores de sólidos sob as superfícies. Logo, o aumento da produtividade é explicado levando em consideração a mecânica dos fluidos. O depósito de substâncias sólidas nas superfícies de permeio dos fluidos acarreta em irregularidades nas superfícies, prejudicando o escoamento laminar. O escoamento torna-se então mais turbulento do que se comparado a um fator de incrustação igual a 0,00001. Esse escoamento turbulento é responsável por ampliar o contato do fluido com as áreas de troca térmica, otimizandoa e gerando, portanto, uma maior produtividade.

Para a faixa analisada, obteve-se um ponto ótimo de operação considerando o fator de incrustação igual a $4.10^{-4} \mathrm{~m}^{2} .{ }^{\circ} \mathrm{C} / \mathrm{W}$. Nesse ponto, obteve-se um GOR igual a 7,410 e um SEC igual a $96,0 \mathrm{kWh} / \mathrm{m}^{3}$, encontrando assim uma operação com maior eficiência que Barraza [14].

Sendo assim, é possível comparar a modelagem utilizada com situações reais e aplicáveis. Como visto anteriormente, a demanda por novas tecnologias já vem surgindo no Brasil. Em função das variáveis analisadas é possível obter uma produção que varia de 0,1138 a $0,1244 \mathrm{~m}^{3} / \mathrm{s}$, o que representa uma produção considerável e capaz de suprir muitas demandas.

Dada a demanda estabelecida pelo edital da Prefeitura de Fortaleza [12], estabeleceu-se um parâmetro de produção de $1 \mathrm{~m}^{3} / \mathrm{s}$. Contudo, o modelo em questão ainda não se encontra adequado para suprir essa necessidade. Mesmo assim, em comparação com outros modelos de MED vistos anteriormente, a produção encontrada por Barraza [14] é notável, pois se aproxima muito do desejado.

É possível perceber ainda que o modelo já se aproxima de um modelo adequado a Fortaleza. Afinal, de acordo com Jesus [13], a temperatura média da água do mar em Fortaleza varia de 26 a $28^{\circ} \mathrm{C}$, enquanto o sistema estudado opera com uma entrada de $33^{\circ} \mathrm{C}$. Uma possível análise futura da variação de temperatura para o modelo em questão pode trazer um ganho enorme para este processo, pois adequaria o sistema a diversos litorais com diferentes temperaturas.

Ainda de acordo com Jesus [13], a salinidade média da água da costa nordestina do Brasil gira em torno de $37,2 \mathrm{~g} / \mathrm{kg}$. Sendo assim, a variação encontrada acima engloba essa faixa, podendo o processo ser aplicado nesse caso.

Para a adaptação do processo às necessidades de processos como o esperado pela Prefeitura de Fortaleza [12], seria necessário a adaptação do processo com, por exemplo, a adição de um préaquecedor no sistema com a finalidade de elevar a temperatura da água do mar à temperatura de 
operação. Porém, ainda assim, é possível perceber que o processo é efetivo em termos de produção de água, sendo quase um terço da água transformada em água fresca, aproximadamente $32 \%$.

O consumo de água médio em Fortaleza é $10,57 \mathrm{~m}^{3} / \mathrm{s}$ [53], porém a prefeitura deseja suprir apenas uma demanda de $1 \mathrm{~m} 3 / \mathrm{s}$, representando 10,59\% do consumo de água da cidade. É possível também considerar a instalação de uma série de plantas. Para a demanda estabelecida [12], seria necessária a instalação de nove plantas operando paralelamente. Ainda, levando em conta uma tarifa igual a $\mathrm{R} \$ 0,83300$ [54], o processo em questão apresentaria custo operacional de $\mathrm{R} \$ 81,7173 / \mathrm{m}^{3} \mathrm{de}$ água fresca produzido, desconsiderando outros encargos de produção.

Porém, é possível otimizar esse custo. Considerando um acoplamento de sistemas com a finalidade de gerar economias energéticas no sistema, essa produção teria seu consumo energético reduzido. Dessa forma, o custo de produção seria entre $\mathrm{R} \$ 1,66$ e $\mathrm{R} \$ 2,08 / \mathrm{m}^{3}$ de água fresca produzido.

\section{Conclusões}

Diante do exposto, é possível perceber que o MED é um sistema de dessalinização promissor, uma vez que se trata de um sistema que apresenta demanda e eficiência energéticas muito boas se comparadas a outros métodos, em especial pelo seu potencial de autossuficiência. Além de não requerer pré-tratamento complexo por não utilizar de membranas e por não ser operado a altas temperaturas. $\mathrm{O}$ investimento em pesquisa nessa área vem crescendo e apresentando bons resultados.

O modelo utilizado para estudo de caso apresenta um bom desempenho, além de ser adaptável para a implementação em uma série de possibilidades. Desta forma, estudos de caso na área podem acarretar em modelos práticos que possam suprir as demandas existentes, bem como a adaptação de métodos como o em questão.

Como perspectiva de trabalhos futuros, espera-se desenvolver a adequação do modelo para as necessidades de Fortaleza-CE, bem como uma análise paramétrica mais robusta para favorecer parâmetros de projeto para seu estudo e implementação. Ferramentas como o EES apresentam um suporte que a academia precisa para desenvolver tais pesquisas. Além disso, sugere-se que, posteriormente, comparem-se métodos entre softwares, como, por exemplo, o software Aspen, que é uma ferramenta muito utilizada no meio acadêmico.

\section{Referências}

[1] Khawaji, A. D.; Kutubkhanah, I. K.; Wie, J. M. Advances in seawater desalination technologies. Desalination, v. 221, n. 1-3, p. 47-69, 2008.

[2] Rosa, D. J. D. M.; Zilles, R.; Fedrizzi, M. C. Dessalinização de água para uso domiciliar com sistemas fotovoltaicos. In: IV CONGRESSO BRASILEIRO DE ENERGIA SOLAR E V CONFERÊNCIA LATINO-AMERICANA DA ISES 2012, São Paulo. Anais. São Paulo, 2012.

[3] Souza, J. C. S., Segurança Hídrica e Planejamento, Revista Água -ABAS (Associação Brasileira de Águas Subterrâneas), Ano 7, n. 43, Janeiro - Fevereiro, 2015.

[4] MMA - Ministério do Meio Ambiente, Programa Água Doce-Documento Base, Secretaria de Recursos Hídricos e Recursos Urbanos, Brasília -DF, 2012.

[5] Barros, M., A solução que vem do mar, Revista Veja, Edição 2426, ano 48, n 20, pág 74, 2015. [6] El-Dessouky, H. T.; Ettouney, H. M., Fundamentals of Salt Water Desalination, 1st edition, Elsevier, Amsterdam, 2002.

[7] Karagiannis, I. C.; Soldatos, P. G. Water desalination cost literature: review and assessment. Desalination, v. 223, n. 1-3, p. 448-456, 2008.

[8] Frigeri, J. A.; Bianchi, M.; Backes, R. G. Um estudo sobre o uso das técnicas de simulação no processo de elaboração e execução dos planejamentos estratégico e operacional. ConTexto, v. 7, n. 12, p. 1-24, 2007. 
[9] Al-Karaghouli, A.; Kazmerski, L. L. Energy consumption and water production cost of conventional and renewable-energy-powered desalination processes. Renewable and Sustainable Energy Reviews, v. 24, p. 343-356, 2013.

[10] Souza, L. Análise térmica de um dessalinizador de múltiplo efeito para obtenção de água potável. 72 p. Dissertação (Mestrado) - Centro de Tecnologia, Universidade Federal da Paraíba, João Pessoa, 2002.

[11] Guerreiro, M. L. F. B. Dessalinização para produção de água potável - Perspectivas para Portugal. 80 p. Dissertação (Mestrado) - Faculdade de Engenharia, Universidade do Porto, Porto, 2009.

[12] CAGECE.; Edital PMI da Dessalinização; 2017; https://www.tratamentodeagua.com.br/wpcontent/uploads/2017/03/cagece-pmidesal-edital.pdf , acessada em outubro de 2018.

[13] Jesus, A. C. D. L. Estudo das vaiáveis oceanográficas na área de influência do terminal marítimo de passageiros do Porto de Fortaleza - Praia Mansa, Ceará, Brasil. 136p. Dissertação (Mestrado) - Instituto de Ciência do Mar, Universidade Federal do Ceará, Fortaleza, 2014.

[14] Barraza, R. Solar Dessalination Systems, Research and Modeling Process. 230 p. Dissertação (Mestrado) - University of Wisconsin, Madison, 2011.

[15] Semiat, R. Energy issues in desalination processes. Environmental Science and Technology.42(22), 2008.

[16] Hamed, O. A.; Mustafa, G. M.; Bamardouf, K.; Al-Washmi, H. Prospects of improving energy consumption of MSF distillation process. In: Fourth annual workshop on water conservation in the Kingdom, Dhahran, S.A: April; 2001.

[17] Darwish, M. A.; Yousef, F. A.; Al-Najem, N. M. Energy consumption and costs with a multistage flashing (MSF) desalting system. Journal of Desalination; 97:285-302. 1997.

[18] Sommariva, C.; Baorsani, R.; Butt, M. I.; Sultan, A. H. Reduction of power require- ment for MSF desalination plants: the example of Al-Taweelah B. Journal of Desalination;108:37-42. 1996. [19] Hernandez-Gaona, C.; Hernandez, S. Comparison of energy consumptions and total annual costs between heat integrated and thermally linked distillation sequences. Chemical and Biochemical Engineering Quarterly;B18(2):137-43. 2004.

[20] Armines. Technical and economic analysis of the potential for water desalination in the Mediterranean region, RENA-CT94-0063, France; 1996.

[21] Lachish, U. Osmosis and thermodynamics. American Journal of Physics;75(11). 2007.

[22] Avlonitis; S. A.; Kouroumbas, K.; Vlachakis, N. Energy consumption and mem- brane replacement cost for seawater RO desalination plants. Desalination;157:151-8. 2003.

[23] Al-Karaghouli, A.; Renne, D.; Kazmerski, L. L. Technical and economic assessment of photovoltaic-driven desalination systems. Renewable Energy, v. 35, n. 2, p. 323-328, 2010.

[24] Adiga, M.R.; Adhikary, S. K.; Narayanan, P.K.; Harkare, W. P.; Gomkale, S. D.; Govindan, K. P. Performance analysis of photovoltaic electrodialysis desalination plant at Tanote in the Thar desert. Desalination;67:59-66. 1987.

[25] Kuroda, O.; Takahashi, S.; Kubota, S.; Kikuchi, K.; Eguchi, Y.; Ikenaga, Y.; et al. An electrodialysis seawater desalination system powered by photovoltaic cells. Desalination;67:161-9. 1987.

[26] M. Stroud, Solar Desalination in the Southwest United States: A Thermoeconomic Analysis Utilizing the Sun to Desalt Water in High Irradiance Regions, Master's Thesis, The university of Arizona, May 2012.

[27] L. Mohammed, N. Driss, O. Djamel, Analysis of the Feasibility of Combined Concentrating Solar Power with Multi Effect Desalination for Algerian Cost,International Journal of Renewable Energy Research, vol.7, nr. 1, 2017, pg 1145-1154.

[28] S. Casimiro, J. Cardoso, D. C. Alarcón-Padilla, C. Turchi, C. Ioakimidis, J. F. Mendes, Modeling Multi Effect Distillation Powered by CSP in TRNSYS, Enerdy Procedia, 49, 2014, pg2241-2250.

[29] K. M. Bataineh, Multi-Effect Desalination Plant Combined with Thermal Compressor Driven by Steam Generated by Solar Energy, , Elsevier, 385, 2016, pg 39-52. 
[30] A. Farsi, S. M. H. Mohammadi, M. Ameri, Thermo-Economic Comparison of Three Configurations of Combined Supercritical $\mathrm{CO}_{2}$ Refrigeration and Multi-Effect Desalination Systems, Elsevier, 112, 2017, pg 85-870.

[31] M. T. Mazini, A. Yazdizadeh, M. H. Ramezani, Dynamic Modeling of Multi-Effect Desalination with Thermal Vapor Compressor Plant, Elsevier, 353, 2014, pg-98-108.

[32] M. Ameri, S. S. Mohammadi, M. Hosseini, M. Seifi, Effect of Design Parameters on MultiEffect Desalination System Specifications, Elsevier, 24, 2009, pg 266-283.

[33] A. M. El-Nashar, Predicting Part Load Performance of Small MED Evaporators - A Simple Simulation Program and Its Experimental Verification, Elsevier, 130, 2000, pg 217-234.

[34] K. H. Mistry, M. A. Antar, J. H. Lienhard V, An Improved Model for Multiple Effect Distillation, EDS Conference, 2012, Barcelona, Espanha.

[35] P. Talebbeydokhti, A. Cinocca, R. Cipollone, B. Morico, Analysis and Optimization of LTMED System Powered by An Innovative CSP Plant, Elsevier, 413, 2017, pg 223-233.

[36] A. Piacentino, Application of Advanced Thermodynamics, Thermoeconomics and Exergy Costing to a Multiple Effect Distillation Plant: In-depth Analysis of Cost Formation Process, Elsevier, 371, 2015, pg 88-103.

[37] A. Loutatidou, H. A. Arafat, Techno-Economic Analysis of MED and RO Desalination Powered by Low-Enthalpy Geothermal Energy, Elsevier, 365, 2015, pg 277-292.

[38] M. A. Sharaf, A. S. Nafey, L. García-Rodríguez, Thermo-Economic Analysis of Solar Thermal Power Cycles Assisted MED-VC (Multi Effect Distillation-Vapor Compression( Desalination Process, Elsevier, 36, 2011, pg 2753-2764.

[39] L. F. de Souza, Análise Térmica de um Dessalinizador de Múltiplo Efeito para Obtenção de Água Potável, Dissertação de Mestrado, Universidade Federal da Paraíba, Fevereiro 2002.

[40] I. J. Esfahani, A. Ataei, V. Shetty K, T. Oh, J. H. Park, C. Yoo, Modeling and Genetic Algorithm-Based Multi-Objective Optimization of the MED-TVC Desalination System, Elsevier, 292, 2012, pg 87-104.

[41] C. Frantz, B. Seifert, Thermal Analysis of a Multi Effect Distillation Plant Powered by A Solar Tower Plant, Elsevier, 69, 2015, pg 1928-1937.

[42] E. P. Dall, Integrating Desalination with Concentrating Solar Power: Large Scale Cogeneration of Water and Electricity, Masters's Thesis, Stellenbosch University, March 2017.

[43] H. R. Dastgerdi, P. B. Whittaker, H. T. Chua, New MED Based Desalination, Process, for Low Grade Waste Heat, Elsevier, 395, 2016, pg 57-71.

[44] N. H. Aly, A. K. El-Fiqi, Thermal Performance of Seawater Desalination Systems, Elsevier, 158, 2003, pf-127-142.

[45] H. El-Dessouky, I. Alatiqi, S. Bingulac, H. Ettouney, Steady-State Analysis of the Multiple Effect Evaporation Desalination Process, Chem. Eng. Technol. 21, 1998, pg 437-451.

[46] A. O. B. Amer, Development and Optimization of ME-TVD Desalination System, Elsevier, 249, 2009, pg 1315-1331.

[47] P. Palenzuela, A. S. Hassan, G. Zaragoza, D.-C. Alarcón-Padilla, Steady State Model for Multi-Effect Distillation Case Study: Plataforma Solar de Almería MED Pilot Plant, Elsevier, 337, 2014, pg 31-42. 
[48] O.A. Hamed, A.M. Zamamiri, S. Aly and N. Lior, Thermal performance and exergy analysis of thermal

vapor compression desalination systems, Energy Con. Mgmt, 37, 1996, pg 379-387.

[49] R. Bahar, M. N. a. Hawlader, and L. S. Woei, Performance evaluation of a mechanical vapor compression desalination system, Desalination, vol. 166, 2004, pg 123-127.

[50] A. Ophir, F. Lokiec, Advanced MED process for most economical sea water desalination, Desalination 182, 2005, pg 187-198.

[51] M. Darwish, F. Al-Juwayhel, H. K. Abdulraheim, Multi-eect boiling systems from an energy viewpoint, Desalination 194, 2006, pg 22-39.

[52] Darwish, Mohamed \& Abdulrahim, Hassan. (2008), Feed water arrangements in a multi-effect desalting system, Desalination. 228. 30-54. 10.1016/j.desal.2007.05.039.

[53] Diário do Nordeste, Consumo de Água Reduz 21\% em Quatro Anos, disponível em: $<$ http://diariodonordeste.verdesmares.com.br/editorias/metro/consumo-de-agua-reduz-21-emquatro-anos-1.1956363>, acesso em novembro 2018.

[54] ENEL, Tarifas,Taxas e Impostos, disponível em: <https://www.eneldistribuicao.com.br/ce/TaxasETarifas.aspx>, acesso em novembro 2018. 